\title{
Introduction to the Third GEWEX Atmospheric Boundary Layer Study (GABLS3)
}

\author{
Albert A. M. Holtslag
}

Received: 23 April 2014 / Accepted: 28 April 2014 / Published online: 30 May 2014

C Springer Science+Business Media Dordrecht 2014

The atmospheric boundary layer (ABL) plays a dominant role in the exchange of energy, water vapour, trace gases and momentum between the earth's surface and the overlying atmosphere. Consequently, the ABL is an important part of any numerical model in use for atmospheric and climate research, for operational weather forecasting, and for air-quality and wind-energy studies. For all these applications an overall representation is needed for boundary-layer turbulence and near-surface processes, as well as for vertical diffusion above the boundary layer. This representation is typically referred as the parametrization of vertical diffusion and turbulent mixing.

It appears that models at various research groups and operational centres use rather different methods to represent turbulence and vertical diffusion and the reasons behind this diversity are not that easy to unravel. Most likely, this originates for historical reasons due to the outcome of various tuning exercises and to the number of models that have been evaluated against observations in the past. In addition, modellers often have different opinions on the complexity needed to represent atmospheric turbulence and vertical diffusion processes in weather forecast and climate models (Holtslag et al. 2013). This directly affects the model performance of near-surface weather variables such as the 2-m air temperature and 10-m wind speed as well as boundary-layer depth, and the forecasting of low-level clouds and fog (e.g., Sandu et al. 2013, 2014; Zhang et al. 2014).

The boundary-layer depth and the height variation of boundary-layer wind and turbulence also directly affect air quality and tracer concentrations near the surface (e.g, Karipot et al. 2008), the transport of aerosols and dust (e.g. Fiedler et al. 2013) and wind-energy applications (e.g., Storm et al. 2009). The ABL also plays an important role in the re-analysis (e.g., Tastula et al. 2013) and understanding of polar climates (e.g., Atlaskin and Vihma 2012; Sterk et al. 2013), as well as the so-called Arctic amplification (e.g., Esau et al. 2012). In addition, McNider et al. (2012) study the stable boundary layer over land and show that this coupled system can be very sensitive to changes in greenhouse gas forcing, surface roughness, heat capacity, and wind speed.

A. A. M. Holtslag $(\bowtie)$

Meteorology and Air Quality, Wageningen University, Wageningen, The Netherlands

e-mail: bert.holtslag@wur.nl 
To understand the basis for the various parametrizations and to make a critical evaluation of the various schemes, model inter-comparison studies were organised within the GEWEX Atmospheric Boundary Layer Study (GABLS). The objective of GABLS is to improve the representation of the atmospheric boundary layer in regional and large-scale atmospheric models. As such, GABLS provides a platform for model inter-comparison and development to benefit studies of weather, climate, air quality, wind energy and other applications. The focus of GABLS has so far been on the stable boundary layer (SBL) over land and on the representation of the diurnal cycle under clear skies. As such, three inter-comparison studies have been organized in which single-column model (SCM) versions of atmospheric models are compared with observations and fine-scale (large-eddy) simulations (LES). The cases are based on observations taken in the Arctic, Kansas (USA) and Cabauw (The Netherlands).

The first two benchmark cases GABLS1 (Holtslag 2006; Beare et al. 2006; Cuxart et al. 2006) and GABLS2 (Svensson et al. 2011) had a more academic set-up and the SCMs were forced with prescribed surface temperatures and simplified geostrophic winds. From these previous studies it was found that especially the complexity of real world large-scale forcing and the lack of interaction with the surface make it difficult to confront models with observations. Moreover, the transitions at sunset and sunrise are difficult to simulate correctly. Holtslag et al. (2007) showed that the spread in results using various SBL parametrizations tends to decrease when interaction with the surface is allowed instead of using prescribed surface temperature as a lower boundary condition. This suggests that feedbacks with the land surface are very important and need to be taken into account for a proper evaluation with observations (see also Steeneveld et al. 2006). Thus, the GABLS3 case addresses the issues of large-scale forcing, the interaction with the surface, transitions and the direct evaluation of models with observations.

This special issue of Boundary-Layer Meteorology contains four papers dealing with GABLS3. The description of the SCM case, details of the selection criteria and the composition of the large-scale forcing are documented in Bosveld et al. (2014a). They benefited from Baas et al. (2010) who did an extensive study on the set-up and selection of an appropriate case study from the multiyear Cabauw dataset.

The subsequent paper by Bosveld et al. (2014b) deals with the inter-comparison of nineteen single-column models from eleven institutes with field data. Twelve of the models participated also in GABLS2. The models varied with respect to application, resolution and parametrization of the fundamental processes. Some of the models were run with varying turbulence schemes, while other aspects of the models remained the same. The SCMs were run with full physical interaction, e.g. interaction with their own soil vegetation and radiation schemes and show striking differences. Interestingly all models systematically underestimate downward longwave radiation, which seems to be mostly related to the representation of the temperature and humidity profiles in the SBL. Besides standard model comparisons with observations, the authors introduce novel process diagrams to better understand and interpret their findings and the relative importance of small-scale processes in the SBL.

Within GABLS3 also an inter-comparison of LES models has been organized. The set-up and findings are given in Basu et al. (2012) and other results will be reported elsewhere. In a third paper Edwards et al. (2014) study the impact of radiation on boundary-layer evolution in the morning transition using two LES models for GABLS3. Interestingly, with atmospheric radiation included, the developing mixed layer grows significantly more quickly. At $4 \mathrm{~h}$ after the transition the mixed layer is roughly $40 \%$ deeper and the resulting profiles of potential temperature and specific humidity are in better agreement with observations. These simulations demonstrate that nocturnal radiative processes can have an important effect on the morning transition and 


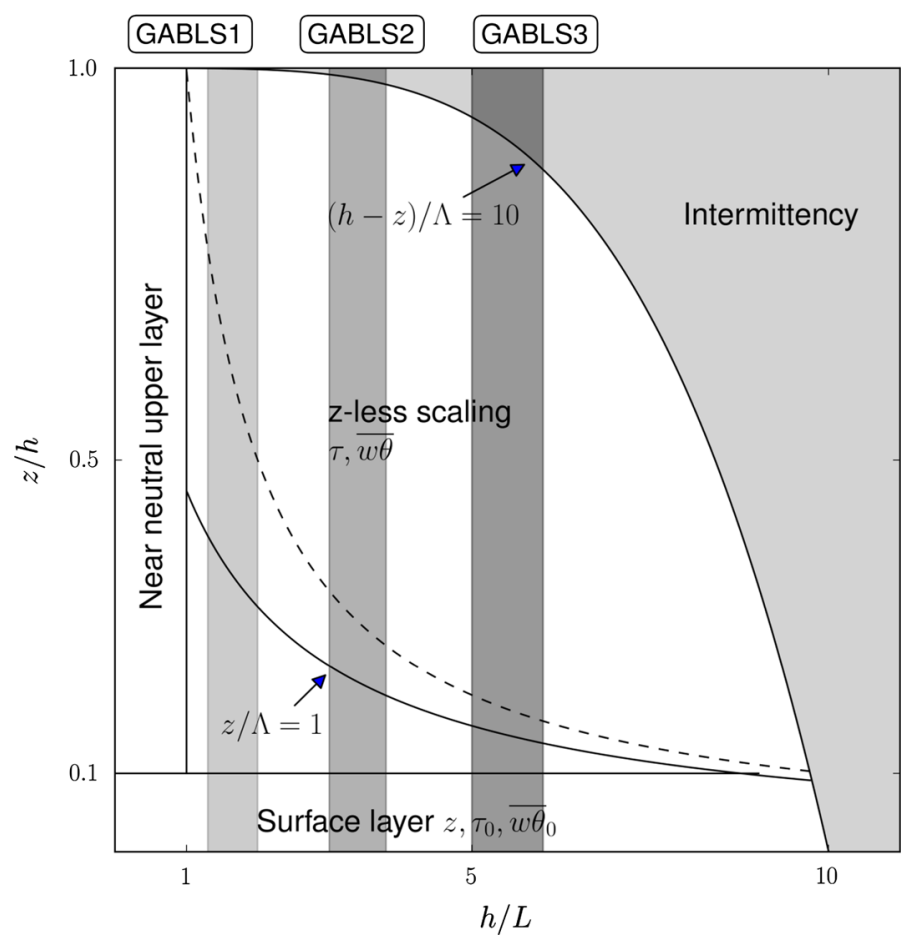

Fig. 1 Typical nighttime stability conditions in the three GABLS benchmark studies as indicated by grey vertical columns in the stability diagram for the stable boundary layer by Holtslag and Nieuwstadt (1986) and as modified for GABLS by Moene et al. (2011). Here, $z$ is height, $h$ is SBL depth, $L$ is the Obukhov length, $\Lambda$ is the local Obukhov length

that they should be considered in future large-eddy simulations of the morning transition.

The paper by Kleczek et al. (2014) uses the GABLS3 case to evaluate the performance of the popular three-dimensional Weather Research and Forecasting (WRF) mesoscale model, in particular the performance of the planetary boundary-layer (PBL) parametrizations. Note that the WRF model (version 3.4.1) contains 12 different PBL parameterizations, most of which have been only partially evaluated with field data. Overall the utilized configurations within the WRF model gave rather good representations of the near-surface variables and vertical profiles, without the additional use of observations (e.g. data assimilation). However, the model results do reveal substantial differences between the PBL schemes.

From the three GABLS benchmarks it became clear that operational models show too much mixing resulting in boundary layers that are too deep (GABLS1), downward sensible heat fluxes that are too large and low-level jets that are too weak (GABLS2 and GABLS3). This obviously also affects the diurnal cycle. By carefully selecting a case and prescribing the atmospheric forcings and allowing for land-surface interaction, it is possible to guide the models in such a way that a useful comparison with observations is possible (GABLS3). However, confronting boundary-layer models with observations remains a difficult and challenging task.

Inspired by the GABLS benchmark results, modelling groups at ECMWF, the UK Met. Office, Meteo-France, the HIRLAM project and elsewhere have been encouraged to study and improve their representation of the stable boundary layer in particular. It is clear that 
Box 1 Future directions and challenges for boundary-layer activities (after Holtslag et al. 2013)

- Enhance the activities and interactions between academia and operational modeling centres, and also engage the climate and air-quality communities

- Study the relation between enhanced mixing in operational models and weather forecast scores, and involve the interaction with other processes

- Investigate the role of land-surface heterogeneity in the coupling with the atmosphere

- Develop and evaluate large eddy simulation models with interactive land-surface and radiation processes for the full range of stabilities

- Advance the understanding of model behavior by creating a climatology of boundary-layer relevant parameters, i.e. stability classes, boundary-layer depth, and surface fluxes

- Initiate further work on the understanding and modelling of the diurnal cycles, in particular the morning and evening transitions

- Develop and test parametrizations for the very SBL when turbulence is not the dominant driver

this issue is still not fully solved and needs further attention. It also appears that changes in the mixing formulation may have strong impacts on the representation of fog and clouds, as well as vertical diffusion in the atmosphere above the boundary layer. Also the GABLS benchmarks are increasingly being used for model development (Buzzi et al. 2011), more complex case studies (e.g., Sterk et al. 2013) and for applications such as particle dispersion (e.g., Weil 2010).

Figure 1 gives the typical (nighttime) stability conditions in the three GABLS benchmark studies as indicated by grey vertical columns in the stability diagram for the SBL by Holtslag and Nieuwstadt (1986) and as modified for GABLS by Moene et al. (2011). In the future we foresee studying the boundary layer that has a stronger stratification, as recommended by participants of the ECMWF-GABLS workshop (Beljaars et al. 2012). Boundary layers over heterogeneous landscapes (such as in Lindenberg, Germany and Sodankylä, Finland) provide additional complexities and challenges.

Finally, it is recommended to further integrate boundary-layer activities with modellers at weather forecast and climate centres, for instance by facilitating regional model intercomparisons such as in ARCMIP (Tjernström et al. 2005) and to acquire and compare shortterm forecasts from full general circulation models for the study point of interest. Box 1 summarizes future challenges as taken from the GABLS overview of Holtslag et al. (2013).

Acknowledgments The current text is partly based on Holtslag et al. (2012, 2013). The author thanks Gunilla Svensson for co-chairing GABLS, the coordinators and contributors to the three GABLS model inter-comparisons, all staff involved in gathering and analysing the field data, the participants of the GABLS workshops and meetings during the years as well as the hosting organisations. Finally, Gert-Jan Steeneveld is acknowledged for suggestions on a draft of the above text and Arnold Moene for updating Fig. 1.

\section{References}

Atlaskin E, Vihma T (2012) Evaluation of NWP results for wintertime nocturnal boundary-layer temperatures over Europe and Finland. Q J R Meteorol Soc 138:1440-1451

Baas P, Bosveld FC, Lenderink G, van Meijgaard E, Holtslag AAM (2010) How to design single-column model experiments for comparison with observed nocturnal low-level jets? Q J R Meteorol Soc 136:671-684

Basu S, Holtslag AAM, Bosveld FC (2012) GABLS3 LES intercomparison study. ECMWF/GABLS workshop on "diurnal cycles and the stable atmospheric boundary layer". ECMWF, pp 75-82. http://www.ecmwf.int

Beare RJ, MacVean MK, Holtslag AAM, Cuxart J, Esau I, Golaz J-C, Jimenez MA, Khairoutdinov M, Kosovic B, Lewellen D, Lund TS, Lundquist JK, McCabe A, Moene AF, Noh Y, Raasch S, Sullivan PP (2006) 
An intercomparison of large-eddy simulations of the stable boundary layer. Boundary-Layer Meteorol 118:247-272

Beljaars ACM, Holtslag AAM, Svensson G (2012) Diurnal cycles and the stable boundary layer. In: ECMWF workshop proceedings on "diurnal cycles and the stable boundary layer", 7-10 Nov 2011. http://www. ecmwf.int

Bosveld FC, Baas P, van Meijgaard E, de Bruijn EIF, Steeneveld GJ, Holtslag AAM (2014a) The third GABLS intercomparison case for evaluation studies of boundary-layer models, Part A: case selection and set-up. Boundary-Layer Meteorol (this volume)

Bosveld FC, Baas P, Steeneveld GJ, Holtslag AAM et al (2014b) The third GABLS intercomparison case for evaluation studies of Boundary-Layer models, Part B: results and process understanding. Boundary-Layer Meteorol (this volume)

Buzzi M, Rotach MW, Raschendorfer M, Holtslag AAM (2011) Evaluation of the COSMO-SC turbulence scheme in a shear-driven stable boundary layer. Meteorol Z 20:335-350

Cuxart J, Holtslag AAM, Beare RJ, Bazile E, Beljaars A, Cheng A, Conangla L, Ek M, Freedman F, Hamdi R, Kerstein A, Kitagawa H, Lenderink G, Lewellen D, Mailhot J, Mauritsen T, Perov V, Schayes G, Steeneveld G-J, Svensson G, Taylor P, Weng W, Wunsch S (2006) Single-column model intercomparison for a stably stratified atmospheric boundary layer. Boundary-Layer Meteorol 118:273-303

Edwards JM, Basu S, Bosveld FC, Holtslag AAM (2014) The impact of radiation on the GABLS3 large-eddy simulation. Boundary-Layer Meteorol (this volume)

Esau I, Davy R, Outten S (2012) Complementary explanation of temperature response in the lower atmosphere. Environ Res Lett 7:044026

Fiedler S, Schepanski K, Heinold B, Knippertz P, Tegen I (2013) Climatology of nocturnal low-level jets over North Africa and implications for modeling mineral dust emission. J Geophys Res 118:12

Holtslag AAM (2006) GEWEX Atmospheric Boundary-Layer Study (GABLS) on stable boundary layers. Boundary-Layer Meteorol 118:243-246

Holtslag AAM, Nieuwstadt FTM (1986) Scaling the atmospheric boundary layer. Boundary-Layer Meteorol 36:201-209

Holtslag AAM, Steeneveld GJ, van de Wiel BJH (2007) Role of land-surface temperature feedback on model performance for the stable boundary layer. Boundary-Layer Meteorol 125:361-376

Holtslag AAM, Svensson G, Basu S, Beare B, Bosveld FC, Cuxart J (2012) Overview of the GEWEX Atmospheric Boundary Layer Study (GABLS). In: ECMWF workshop proceedings on "diurnal cycles and the stable boundary layer", 7-10 Nov 2011, pp 11-23. http://www.ecmwf.int

Holtslag AAM, Svensson G, Baas P, Basu S, Beare B, Beljaars ACM, Bosveld FC, Cuxart J, Lindvall J, Steeneveld GJ, Tjernstrom M, van de Wiel BJH (2013) Stable atmospheric boundary layers and diurnal cycles_challenges for weather and climate models. Bull Am Meteorol Soc 94:1691-1706

Karipot A, Leclerc MY, Zhang G, Lewin K, Nagy J, Starr G (2008) Influence of nocturnal low-level jet on turbulence structure and $\mathrm{CO}_{2}$ flux measurements over a forest canopy. J Geophys Res 113:D10102

Kleczek MA, Steeneveld GJ, Holtslag AAM (2014) Evaluation of the weather research and forecasting mesoscale model for GABLS3: impact of boundary-layer schemes, boundary conditions and spin-up. Boundary-Layer Meteorol (this volume)

McNider RT, Steeneveld GJ, Holtslag AAM, Pielke RA Sr, Mackaro S, Pour-Biazar A, Walters J, Nair U, Christy J (2012) Response and sensitivity of the nocturnal boundary layer over land to added longwave radiative forcing. J Geophys Res 117:D14106

Moene AF, Baas P, Bosveld FC, Basu S (2011) LES model intercomparisons for the stable atmospheric boundary layer. In: Quality and reliability of large-eddy simulations II. ERCOFTAC series, vol 16, Part 1, pp 141-148

Steeneveld GJ, van de Wiel BJH, Holtslag AAM (2006) Modeling the evolution of the atmospheric boundary layer coupled to the land surface for three contrasting nights in CASES-99. J Atmos Sci 63:920-935

Sterk HAM, Steeneveld GJ, Holtslag AAM (2013) The role of snow-surface coupling, radiation, and turbulent mixing in modeling a stable boundary layer over Arctic sea ice. J Geophys Res 118:1199-1217

Sandu I, Beljaars A, Bechtold P, Mauritsen T, Balsamo G (2013) Why is it so difficult to represent stably stratified conditions in numerical weather prediction (NWP) models? J Adv Model Earth Syst 5:117-133

Sandu I, Beljaars A, Balsamo G (2014) Improving the representation of stable boundary layers. ECMWF News1 138:24-29. http://www.ecmwf.int

Storm B, Dudhia J, Basu S, Swift A, Giammanco I (2009) Evaluation of the Weather Research and Forecasting model on forecasting low-level jets: implications for wind energy. Wind Energy 12:81-90

Svensson G, Holtslag AAM, Kumar V, Mauritsen T, Steeneveld GJ, Angevine WM, Bazile E, Beljaars A, de Bruijn EIF, Cheng A, Conangla L, Cuxart J, Ek M, Falk MJ, Freedman F, Kitagawa H, Larson VE, Lock A, Mailhot J, Masson V, Park S, Pleim J, Söderberg S, Zampieri M, Weng W (2011) Evaluation of the 
diurnal cycle in the atmospheric boundary layer over land as represented by a variety of single column models - the second GABLS experiment. Boundary-Layer Meteorol 140:177-206

Tastula E-M, Vihma T, Andreas EL, Galperin B (2013) Validation of the diurnal cycles in atmospheric reanalyses over Antarctic sea ice. J Geophys Res 118:4194-4204

Tjernström M, Žagar M, Svensson G, Cassano J, Pfeifer S, Rinke A, Wyser K, Dethloff K, Jones C, Semmler T (2005) Modeling the Arctic Boundary Layer: an evaluation of six ARCMIP regional-scale models with data from the SHEBA project. Boundary-Layer Meteorol 117:337-381

Weil JC (2010) Stable boundary layer modeling for local and regional-scale meteorological models. In: 19th Symposium on boundary layers and turbulence, Keystone

Zhang X, Musson-Genon Luc, Dupont Eric, Milliez Maya, Carissimo Bertrand (2014) On the influence of a simple microphysics parametrization on radiation fog modelling: a case study during Paris fog. BoundaryLayer Meteorol 151:293-315 